\title{
Cubical Anatomy of Several Ducts and Vessels by Injection Method of Acrylic Resin
}

\author{
III. On the vascular system of the spleen \\ in some mammals
}

\author{
By \\ Yoshikuni Ohta \\ Department of Anatomy, Osaka Dental College, Osaka. \\ (Director: Prof. Y. Taniguchi) \\ With 61 figures in 6 plates
}

Argument of this research was announced at 59th Annual Session of the Japanese Association of Anatomists, May, 1954, Maebashi.

\section{Preface}

On the internal vascular system of the spleen, a great number of scholars has made researches by various methods-morphological, physiological and experimental pathological. But some definite conclusions on the circulation have not been drawn even now, and it has been disputed ardently about various theories. Until now, many methods have been taken in order to explain the very problems morphologically, and they could be divided into three as follows:-

1. Injection method; Methods populary employed from early days. Here, injections are done into either the splenic artery or the vein, or both, of a living body or a cadavar with coloured gelatin, indian ink, in very few cases some matters not mixed with the tissue fluid (asphalt or plastics), and observations are made on serial sections and corrosion specimens. Those are excellent techniques as directions of the vessels are clearly observed. It is, however, difficult to observe the reticulum and arterio-venous intermediates, in view of the open or the close circulation theory, which is the most important interesting point of the splenic circulation, since there are much fears of artificial 
products, on account being ordinary injecting matters soluble in water to disperse into tissues, the time lay after death, the sponginous struc. ture of the spleen, and the deficiency of the techniques. In addition, much difficulty is experienced and patience required in reconstructing the sections.

2. Silver impregnation; As a device to avoid the artificialities by the in ection, the splenic circulating route is observed on silver impregnated reticular constructions, and sometimes may be used in combination with injection. But it is regrettably unable to response to the physiological prosperities.

3. Transillumination method; Since the two devices do not yet elucidate the circulation, an attempt to observe it in a living body is made. Still it seems to be hard to observe particularly the fine portions.

Injection, by author, of acrylic resin was made as an attempt to demonstrate and observe cubically the splenic vasculature, especially the finer portions under the lymph-sheathed artery and the internal venous system, in some mammals. In the literatures, Hoy e $r$ (1893), M a 11 ('02) injected asphalt solution into the dog's splenic vessels and observed them on the sections. Blechs ch midt ('38) practised the plastoid injection in man and surveyed on its corrosion specimens. There may be no achievement which observed the splenic fine portions on the corrosions but his one.

\section{Materials and Methods}

Followings were the mammals used for this research : 23 dogs, 8 cats, 3 cattle, 3 pigs, 3 goats, 5 rabbits and 2 human bodies. In injecting acrylic resin and producing a cubical corrosion specimen, the method published by $\mathrm{Taniguchi}, \mathrm{Ohta}$ and $\mathrm{Tajiri}$ ('52) and its supplement ('55), were adopted. The animals were led to depletion death, in situ a cannula was inserted into the coeliac artery through the thrracic aorta and the injection given after ligating all arterial branches except those enter into the splenic hilus. Splenic veins were injected directly or through the portal vein. In advance of the injection, in many cases cold or warm physiological solution of sodium chloride or distilled water was very slowly irrigated. The injecting order in almost cases, was the arteries, then the veins, but sometimes vice versa in dogs, cats and cattle. The viscosity of the resin used was $100-125$ centipoise $\left(20^{\circ} \mathrm{C}\right)$ and the injecting pressure in all cases 
was below $500 \mathrm{~mm} \mathrm{Hg}$ for the arteries and below $200 \mathrm{~mm} \mathrm{Hg}$ for the veins. The resin injection was extremely difficult, and although 3-4 times subjects as many as the example above-mentioned were experienced, the perfect specirrens constantly were not obtainable, especially, of the veins, so particularly difficult to do throughout the entire spleen. In fact, the spleen being a sponginous organ, a sudden injection and a high viscosity caused ruptures of the fine vessels in the spleen. The injection into the veins was often impossible due to the many venous vulves in front of the hilus. Hence the observation was made in the cases which were injected with a regular viscosity and the abovementioned pressure.

On the one hand the resin injected spleens were prepared to the corrosions, on the other always fixed part of them in $10 \%$ formalin or Zenker's solution and made it serial celloidin sections of $5 \mu, 30 \mu$ and $70 \mu$ in thickness, and then stained with iron-hematoxylin or Azan, and Bielschowsky's silver impregnation. Further, in all cases non-injected serials were made as control, staining with $\mathrm{H}-\mathrm{E}$ and Azan.

To compare the resin injection with indian ink or colour matters, the following experiments, especially in dogs, were employed : 1) Carmine and methylene blue gelatin solution were injected into the arteries and the veins respectively, in some cases, indian ink into the arteries alone, and made them serial sections. 2) Carbon-black suspension of $10 \%$ glucose solution $(0.2 \mathrm{cc} / \mathrm{kg})$ was injected into the femoral vein, and the dog slaughtered 2 hours later, the resin injection into the splenic arteries and the veins, celloidin serials were made, and the effects were observed comparatively at the region of the carbon-black deposition and the resin injection.

Considering the corrosions as the main object in the observation, the orientation of every vessel as well as the interrelation with the splenic tissue and the vessels, were established on the resin injected serials. Keeping the accent on the views in dog, the comparative observations proceeded, and into details entered on the characteristic regions of the other species except dog.

\section{Observation}

It is to describe about the lymph-sheathed artery, the follicular artery, the pulp artery or the penicillar artery, the ellipsoid and the venous origin in each animal. 


\section{A. Arterial system}

1. Dog: The lymphatic sheath is underdeveloped compared with the lymphatic follicle. The artery detached from the trabecula is soon covered with the lymphatic sheath, run along its axis or rather eccentric and split into several branches within the sheath. The follicles chiefly develop at the branching portions of the artery, so the more the follicle develops, the more the central artery appears eccentrically (Figs. 3, 4, 6). Accordingly, the name, central artery is unsuitable, and also to consider the whole artery covered with the lymphatic sheath as the central artery, is improper. This fact is recognizable in every animal, so the portion covered with the sheath would be named lymph-sheathed artery and the portion passing through the follicle named follicular artery, following some seniors.

The arterial plexuses in the lymphatic sheath and the follicle consist of three kinds of the branches: 1 ) Fine capillaries $(7-30 \mu)$ directly from the follicular artery (Figs. 3, 4, 5, 6). 2) Capillaries from one or two stems subrectangularly out of the follicular artery (Figs. 4,6), and from the branches running parallel with the arterioles branched at proximal portion of the follicle (Figs. 3, 7). 3) In a few cases, capillaries recurred from the penicillar arteries into outer portion of the follicle (Fig. 3).

All these capillary plexuses in the follicles and the sheath, open on spaces of their mantle and halo, spreading to the outside (Figs. 3, $4,6,7,8,11$ ). Although very few, a branch derived from a lymphsheathed artery at this side of the follicle, reaches the halo, making a detour, and opens on the spaces (Fig. 3). Enclosed with the endotherial cells (Fig. 9), can these spaces be casted as congregations (100$200 \mu$ ) of many joined chamberlets in shape of small drops, hanging drops $(15-33 \mu)$ and short spurs, and they present a compressed form compressed by the red splenic pulp (Figs. 3, 4, 12). So the so-called splenic sinuses are not found in the mantle and the halo of the follicle. Even if it is injected into the vein and then the artery, these spaces are still filled with the resin through the artery, and the resin through the vein is recognized in the outside, and several connections are observed between both (Figs. 4, 8, 11, 12). So, the former would be differentiated as the arterial sinusoid.

The lymph-sheathed artery branches within or right behind the sheath, and these branches are different in their length.

Ellipsoidal central capillaries are not so monotonous, and the wall of which has orifices as some literatures. The resin attains the 
periglumar mesh-spaces (periglumäre Maschenräume, T. Imai) coming out of the orifices, so on casts the whole ellipsoid appears as pineal cone (ca. $100 \times 20 \mu$ ), ovoid pointed at the distal end, projectile and globe (Figs. 10, 11, 14, 15, 16, 17, 21). Observed the internal structures of the ellipsoid with imperfect injected corrosions and injected sections:-Central capillary shoots out branches as spines or spurs 2.5-4.5 $\mu$ ), which continue to the periglumar mesh-spaces. Cast of the mesh-spaces appears as irregular drops and resemble cast of the arterial sinusoids around the follicle, but still smaller (Figs. 11, 14, 15, 16, 17, $18,21)$.

It is also observed, ellipsoids present numerous in the red pulp around the follicle, so the resin from the wall of the ellipsoids contacts with that of the arterial sinusoids. In such cases, often, one or two of the penicillar arteries reccur towards the follicular peripheries and open on the arterial sinusoids (Fig. 11).

Terminal capillaries after the ellipsoids proceed meandering, majority of them terminates with blind ampullae (12-25 $\mu$ ) like clubs (corresponding to Thoma's ampullae, Figs. 13, 16, 18), also, blind ones without amplifying, and ones connecting directly with the splenic sinus (Fig. 13).

2. Cat: The whole arterial system displays strong crookedness and meandering. The development of the lymphatic sheath is not so good that the arterial plexus in it is scarcely recognized, and the lymph-sheathed artery is fine $(25-45 \mu)$. Follicles are smaller than the dog's, the germinal centre is well developed specially and the mantle thin. The follicular artery passes through the periphery of the germinal centre or the halo and runs in an arc form along the outline of the follicle. So it seems more eccentric than the other animals' (Fig. 50).

The arteries which supply the follicle, directly diverge from the follicular artery in chief; and arterioles out of the origin of the follicular artery go in with. They enter the centre from the mantle and the halo coiling each other, and the capillary plexuses are made of part of them. The vessels that construct the follicular plexus are so thicker $(10-30 \mu)$, than the other animals' (except pig's) that it could be called an arteriolar plexus (Fig. 20). Further, each vessel being crooked and meandering, the mesh appears as a spireme mesh. It proceeds to the periphery of the follicle and opens on the arterial sinusoids of the halo, which pour into venous branches outwards (Fig. 20). 
Shape of the individual sinusoid is different from that of the other animals, a stellate or a short spur (Fig. 23). It is not changed into a small globe or a bubble shape even if the injecting amount through the artery is increased. As the follicle itself is small, sharply outlined follicle surrounded by the arterial sinusoids on the corrosions, is hardly recognized.

Branchings to the penicillar arteries are small in number in shape of so-called penicilli. Separate branchings are observed to be large in number, and strong tortuosities are marked (Fig. 19). No recurrent branch towards the follicle opens on arterial sinusoid around the follicle.

Well developed ellipsoid appears as an ovoid pointed at its distal end (ca. $130 \times 50-100 \mu$ ) on the corrosions, and the resin injected into the regular tissue spaces through the wall of the central capillary is observed. The interior wall of the central capillary is so uneven that irregular knob-like projections on the corrosions are seen sporadically, long or short, thick or thin, in some cases so large that they look like lateral branches of the central capillary (Figs. 22, 27). The resin reaches the periglumar mesh-spaces from these projections via regular routes in the ellipsoid, so the whole ellipsoid appears as a morula-like ovoid. The radiating routes connected with the central capillary are fully observed on the imperfect injected corrosions and after dissecting them (Fig. 27).

Terminal capillaries are considerably fine $(6-8 \mu)$, not bending, and terminate blindly in the red pulp at a short distance dividing into several forks. Amplifying terminals are not recognized, and however the injecting quantity increases, the length of the terminals is not grown and also the direct connection with the venous branches and the terminals not obtained.

3. Cattle: The development of the lymphatic sheath is common, and the follicle is well developed and large in number. The lymphsheathed artery, without tortuosities, divides into follicular arteries.

The lymph-sheathed artery and the follicular artery divide into several branches close each other, and run abreast into the follicle. Accordingly, two or three follicular arteries often are contained in a follicle (Fig. 24, characteristic in cattle).

The arteries which supply the follicle are the capillaries from several follicular arteries (Fig. 24) and from recurrent branches of the penicillars (Fig. 24). The follicular plexuses are not so coarse as the cat's and are constructed with the capillaries whose thicknesses almost even (generally, resemble the dog's, cf. Figs. $24 \& 5$ ). The lymphatic 
sheath behind the follicle is so short that the artery divides into three or five penicillar arteries right behind the follicle. Two branching features are seen on the corrosions, ordinary penicilli (Fig. 25) and unfolded petals or tentacles of an octopus in large angle (Fig. 29), and both are typical. The arteries in penicillar type are straight and long, and run abreast (just like long-hair brush, $15-30 \mu$ in thickness, longest and largest in number in cattle). Two or three of the arteries in octopus type become recurrent branches and open on the arterial sinusoids around the follicle (Fig. 25), corresponding to centripetal arteries by some seniors.

No terminal of the penicillar artery connects with the venous branch. In tracing on the cast their terminals seem closely to touch the wall of the venous branches and often give an impression as if they were the vasa vasorum of the venous branches (Fig. 28), but they are not connected with them. Large injecting quantity through the vein brings the connections between the arterial terminals and the extravasations from the venous originals.

The ellipsoids are not well developed. In examining the long penicillar arteries to their ends on the corrosions, the trace of the ellipsoids is scarcely found, but recognized in comparing them with injected sections. The orifices on the wall of the central capillary and the regular tissue spaces, and through them the resin injected into the periglumar mesh-spaces, resembling the feature of the dog's, are shown.

4. Goat: The development of the lymphatic sheath is the best. Slight meandering are seen in the thick arteries-i.e., from the trabeculars to the folliculars (Fig. 33). The lymph-sheathed artery divides into several branches close each other and run abreast, so a sheath in its transsection contains several lymph-sheathed arteries, and also similarly about the follicular arteries (Fig. 32). Well developed capillary plexuses in the lymphatic sheath are observed, composed of the capillaries diverged directly from the lymphatic arteries and from the arterioles out of them, the meshes being dense and the capillaries uniform in thicknesses (Fig. 32). On the other hand the development of the follicle is worse, the features of the vessels in it appear as the minifieds of the cattle's, but the follicular capillary plexuses are simple unlike the cattle's and are inferior to them in the lymphatic sheath. These plexuses open on the arterial sinusoids in the mantle and the halo spreading to the outwards (Figs. 26, 32). Besides, a branch emerged rectangularly from the follicular artery proceeds to the mantle without dividing and opens on the arterial sinusoids (Fig. 31). The 
sinusoids extend from the halo to part of the red pulp. Individual sinusoid is apart each other and smaller $(12-20 \mu)$ than the other animals', so on the corrosions glanular (Figs. 31, 32).

The branching features of the pencillar arteries resemble the cattle's, but the branching aperture in an octopus type is smaller in num. ber. Three or eight branches are, at times, arranged fan-shapedly in a plane (Figs. 26, 33), and one of them becomes a centripetal artery. The ellipsoids are undergrown and of small size, even regular tissue spaces in them are injected. The terminal capillaries are long generally, as in cattle. Many of them terminate blindly in the red pulp without amplifying and some connect with the venous original branches (Fig. 30).

5. Pig: The lymphatic sheath is stout, but the follicle lesser. The lymph-sheathed artery is tortuous, especially spiral. The branching features of the follicular artery are alike the goat's, the follicle is supplied by the branches split at the proximal portion of and behind the follicle. Capillary plexuses in the sheath and the follicle are coarse, and the capillaries considerably thick. They open on the arterial sinusoids in the mantle and the halo. Particularly, on the corrosions the sinusoids around the sheath are marked.

The arteries behind the follicle are relatively short while those of the cattle and the goat are long. The branching features of the penicillar arteries are ordinary penicillar type and show a spiral running up to ellipsoids (Fig. 34, 36). One or two of the penicillars often open on the arterial sinusoids recurring in an arc form (these branches bear ellipsoids).

The development of ellipsoids is the best, so the emphasis is put on observations of the pig's. The ellipsoids are so large that they are misjudged as part of the arterial sinusoids around the follicle on the corrosions. Casts of perfectly injected ellipsoids appear as morula-like projectiles and elongated ovoids pointed at the distal end (ca. 200x $80 \mu$, Figs. 34, 35, 36, 37). In some of them, the central capillary bifurcates, so often showing a twins-type as if the two ellipsoids adhere at their proximal parts (Herrath's Hülsenkomplex '35, Fig. 39). The central capillary is $7-12 \mu$ in thickness and its wall is not smooth (Figs. 35, 37). The resin reaches the periglumar mesh-spaces through the regular tissue spaces which are continuous to the central lumen radiating in the ellipsoid. The casts of these tissue spaces are shown as spines, short spurs (Figs. 35, 37, 38, 40,43) or their complications, besides many of them are so stout that seem to be the lateral branches 
from the central capillary (Figs. 36, 38, 43). Their thicknesses are 5$10 \mu$, and their ends expand into knobs or goblets. They are identified with the casts of the periglumar mesh-spaces (Figs. 35, 37, 38, 39, 40). One ellipsoid holds five to fifteen spaces or lateral branches, even in long and large one. One or several spaces are only noticed (it may be due to imperfect injection). Dissection of casts of ellipsoids proved that the central capillary traces a zigzag course and has projections on its wall sporadically (Figs. 35, 37, 39).

Capillaries behind the ellipsoid divide into two or three, terminate blindly at a short distance, and amplifying terminals are small in number (Fig. 37). No connection with the venous origin is seen.

6. Rabbit: The development of the lymphatic sheath is general. Follicles are well developed at branching points of arteries, but being close to each other, the capillary plexuses in them are common to the adjacent ones or anastomose. The lymph-sheathed artery is straight and runs in the axis of the sheath. The follicular artery also runs eccentrically (Figs. 41, 42) in the thicker halo (25-45 $\mu$, Fig. 45).

Follicular capillary plexuses are made of, the capillaries from short stems $(10-15 \mu)$ subrectangularly out of follicular arteries, from the folliculars directly and sometimes from the latter at the proximal portion of the follicle. Well developed meshes open on arterial sinusoids in the thick halo spreading towards outside (Figs. 1, 47). Of this plexus in rabbit, interesting observations are obtained as follows:They are arranged in radiating in general, but it is often found that tangential capillaries parallel with the follicular surface anastomose with peripheries of the radiating capillaries in the mantle. Besides, several capillaries diverged radially from these tangentials open on the arterial sinusoids in the halo (Figs. 44, 45, 47). These tangentials are not always one but some of them run parallel with the branches from themselves (Figs. 44, 47), and they do not extend to the halo in every case.

The arterial sinusoids appear as stellates and polygons, but small drops and short spurs are few. They are present in the halo, and no splenic sinuses there (Figs. 1,44, 45, 47). Even if the injections to the vein and then the artery are done, the spaces of the halo are filled with the resin through the artery. The sinusoids connect with the splenic sinuses outwards, especially distinct in rabbit. The connections are observed on the borders between the halo and the red pulp (Figs. 45, 47).

The arteries left the lymphatic sheath are long and straight in 
general. The branching feature is unfolded petals but the aperture narrow. The penicillar arteries are fine $(4-10 \mu)$ and a little tortuous. One of the penicillars recurrs to the follicle passing through the halo and opens on the arterial sinusoids (Fig. 44. May it be a kind of centripetal arteries?) No recurrent branch connects with the follicular artery-i. e., Jä g er's loop.

Almost of the terminals of the penicillars connect with the splenic sinuses attenuated (Fig. 46).

7. Human subject: As the procurement of the fresh spleen of man is hard, the resin injection were experienced on two examples. And at that these subjects had been dead pretty time, the one had got splenitis (C.P.C. examination, white pulp and ellipsoids are degenerated). So, the normal observation could not be obtained partially, only the views being able to regard as the normal will be mentioned.

The development of the lymphatic sheath is common, and the borders between the mantle and the halo, the halo and the red pulp are very obsecure, respectively. The follicles grow at the branching points of the lymph-sheathed arteries, and the follicular arteries are eccentric.

Arteries which supply the follicle are derived from several stems out of the folliculars (Fig. 48). The follicular capillary plexuses are pretty grown, but somewhat lesser than the dog's (Fig. 48, cf. 48 \& 5). The meshes spread towards the peripheries of the follicle and open on the arterial sinusoids in the mantle and the halo though their boundary is not distinct.

Individual sinusoid appears as a water drop or a polygon and is apart each other as in goat and cattle. So, especially on the cast, one or two arterial sinusoids are able to dissect out at ends of follicular capillaries (Figs. 48, 49).

Penicillar arteries are short, and their terminals connects with ends of splenic sinuses large in number (Fig. 2, the most numerous).

Of ellipsoids, it is withheld descriptions, as the definite observation was not obtainable due to the pathological changes.

B. Venous system-especially about the originals.

Although it is considerably difficult to express concretely the definite form of splenic sinuses, casts of them make their differences clear by "compared with each other. No differences are recognized in the splenic pulp vein and the trabecular vein (except their sizes). The questions are the morphological differences in the sinuses and the venous originals. 
1. Dog: Sinuses are well developed. Most of them are cylindrical (short rod) and longer than them of the other animals. Their ends are a little globular and the thicknesses are various, generally $18-32 \mu$, average $25 \mu$ (Figs. 50,51 ).

2. Cat: No sinuses like in dog are recognized. The finest of the venous branches is $25-70 \mu$ in thickness, and curves in bow-shape (Fig. 52). An interesting thing in the cast is that the venous branches bear many isolated or congregated, knobs or buds (14-20 $\mu$, Figs. 5457). This fact suggests that particular feeble portions for the injection pressure, or diverticula are situated on the wall of the venous branches. No branches are recognized beyond these knobs. If amount of the injection increases, the material is easy to effuse from these knobs and turn to homogenious lumps.

3. Cattle: The portions to be able to call sinuses are not recognized. The original venous branches are fine rods. The feature is as if sticking fine rods in the pulp veins of cat and dog. The unit number is not so large as that of the sinuses. The rods are relatively long, $25-30 \mu$ in thickness, branching is scarce, and even if branching it is no more than short appendixes (Figs. 56, 59).

4. Goat and pig: The feature of the venous branches in both resembles each other, and it is further from the aspect as the sinuses compared with the cattle's. It presents similar features as the ordinary thick venous branches shown in the general organs except the spleen. The originals in cattle present rather long rods in shape, but in goat and pig they are hacked-like. Their thicknesses are $40-55 \mu$ in goat, 35-50 $\mu$ in pig (Fig. 53). In these animals, the tendency of the resineffusion into the red pulp is so notable.

5. Rabbit: Sinuses are well developed. They appear as if the complicated form of the dog's, namely, the tips of the rods are elongated, amplified, compressed, forked-that is, heart-shaped, fanshaped, spade-shaped etc., but it is hard to summarize their forms. The thickness of the rod is $12-20 \mu$, the amplifying $30-55 \mu$. These originals anastomose each other and pour into the thicker branches separately or collectively (Figs, 55,58 ).

6. Human subject: Sinuses are well developed. Results of the arterial injection are undesirable in some points as the above, but the venous system was fully studied. Tips of the venous branches are more complicated than those of rabbit-i.e., fan-shaped, chestnutshaped, pear-shaped, plectrum-shaped etc. These sizes are various, 12$20 \mu$ in thickness of the rods, $30-55 \mu$ of the amplifyings (Figs. 60-61, 62). 


\section{Summary and Discussion}

A great number of scholars has been in research on the vasculature of the spleen by means of various methods. Many points, however, are not yet made clear. Especially, various methods have been employed from early days. To use coloured gelatin, indian ink, soluble in water, as materials, is not satisfactory on this research, because they dissolve in the tissue fluid or diffuse into the splenic reticulum. So, the bird blood corpuscle suspension, asphalt and plas: toid which are able to be traced in the tissues, are tried for injection. Up to the present, there may have been no work performed on the corrosions as main subject, about the fine portions, using also the sections injected with the same material.

The results of the author's observations will be now summarized and discussed with works chiefly made by injection methods:-

The artery left the trabecula is enclosed with the lymphatic sheath and continues to branch with the follicles here and there, especially at its branching points. In the sheath it goes along its axial part, but in the follicle so-called central artery passes through the mantle or the halo (J äger, '29, T. I m a i) eccentrically, as I ma i ('38), Snook ('50), Kimura ('52), Maximow ('53) emphasized. So that, by Ima $\mathrm{i}$ and his school the artery enclosed with the lymphatic tissue is named lymph-sheathed artery, the central artery named follicular artery, and S n o o called them lymphatic vessel and eccentric artery, respectively. Author's observations as well agree with their results. It could not be regarded proper to call the artery that goes along the follicle central. Accordingly, it seems to be adequate to name them lymph-sheathed artery and follicular artery, respectively, accepting the seniors'.

In cattle and goat, as the author described, several lymph-sheathed arteries or folliculars run abreast for a short distance within the same lymphatic tissue. They are characteristic in these species, but such a view has not yet been reported, as it might be hard to obtain the fact on the sections alone. In cat, goat and pig, some tortuosities from the .lymph-sheathed artery to its peripheries give a suggestion that the blood-reserving increases and the blood stream retards peculiarly in these species.

In this paragraph, it is discussed about the derivation sources of the follicular arterial plexus and its capillary terminals, which are 
both the foci of the discussion. H u e ck ('28), Jäge r ('29), stated that a recurrent branch of the penicillars divided into capillaries invading the follicle and sometimes communicated with the central artery (Jäg er's vascular loop). O no ('30) stated by his embryological studies on the splenic vasculature that the follicular capillary plexus in a certain stage of the human embryo was made of the recurrent branches, and $I \mathrm{~m}$ a $\mathrm{i}$ also got a similar view in cat, but they are not observed in the Jäg er's loop. Thereafter, K i m u r a studied on this matter in rabbit, guinea-pig and rat, and described that the plexus was constructed with the recurrent branches of the penicillars alone in guinea-pig and rat (penicillar type), and branches out of the periphery of the lymph-sheathed artery came accompanied by them in rabbit (modified penicillar arterial type-compromise). Author's observations are that, the main elements which construct the plexus, though there are variations in the species, are the capillaries out of the arterial branches from the follicular artery (follicular arterial type in rabbit by $\mathrm{Kimura}$ ) and the ones directly from the folliculars, namely, the branches are not limited to the recurrences of ' the penicillars as emphasized. Schweigger-Seidel (1863), $\mathrm{Ky}$ ber (1870), M acNeal et al. ('27) studied on the follicular plexus in rabbit, and $\mathrm{Ky} \mathrm{ber}$ stated, a branch diverged from the main artery in the follicle. In this paper, many branches out of the follicular artery are seen in dog and rabbit, while many branches out of the lymph-sheathed artery at the proximal portion of and behind the follicle in cattle and goat, but few in other species. The follicles develop secondarily within the lymphatic sheath, and it is no wonder their rise and fall depend upon metabolism or acquired diseases of their individual. So, it may be rossible that the branching points of the follicular capillaries are found right before or behind the follicle.

There are few works that have made comparative observations of the capillary mesh in the follicle. Snook stated the capillary plexus in cat is dense and abundant resembling that of dog. In the author's observation, the meshes in dog are the densest. after that of rabbit and the capillaries of the former are fine $(3-10 \mu)$, those in cat are coarse, undergrown and the capillaries are so thick $(10-30 \mu)$ that they seem to be arterioles. These results in cat are opposed to Snook's. It is generally known that the mesh spreads radially towards the periphery of the follicle, as Kölli k e r (1849) described, and $\mathrm{MacNe}$ a 1 et al. stated, the expanse of the mesh was fan-shaped 
or olive-shaped, while the author's results show generally radial but them of cat which show coarse spireme mainly. In rabbit as already described, the tangential capillaries in the mantle and the supermost layer of the centre are considered to correspond to Röhlich's ('33) äusseres Kapillarensystem in mouse, but other seniors did not report such capillaries.

The author described, the spaces which are existent in the halo or mantle of the follicle, filled with the injecting resin through the artery, and they are named arterial sinusoids tentatively. It is observed repeatedly and viewed from various angles on suspicion of artificial products, on the cast and the sections injected with the resin in various degrees, non-injected, coloured gelatin injected sections and the resin injected after injecting indian ink in living body etc.

Literatures on the follicle and its peripheries are abundant. The well developed follicle has a bright germinal centre surrounded by a densely lymphocytes-populated mantle. These two parts are the original white pulp, which has a coarse lymphocytes-populated halo (Kern, Mantel $u$. Hof by J äg er) in a perimeter of them. The halo was named Knötchenrandzone by We iden reich ('01), border zone by Andrew ('46), marginal zone by Alt s chul and $\mathrm{Hamm}$ a s on ('47). Of later years, S nook carried out the silver impregnation to the spleen in some mammals in view of being avoidable to make artificialities by injection methods and thus discribed:-The follicles of mouse, rat, cat, dog, cattle and man have above-mentioned marginal zone, and that is more distinct in man, mouse and dog. Besides cleft-like spaces (marginal spaces) enclosed with endothelial cells, exist between the marginal zone and the follicle, and erythrocytes are held partially in those of dog. Connecting with this work, Andrew described marginal sinus in this region of rat, and $A 1 \mathrm{tschul}$ et al. perifollicular space. S n o ok stated, the follicular capillaries reached the marginal zone and opened on the space. $\mathrm{Hueck}$ stated, these capillaries directly, or via perinoduläre Flutkammer, poured into the sinus. Braus ('24), MacNeal et al., $\mathrm{N}$ is i maru' and $\mathrm{S}$ te g. gerda ('32), T. Ima $i$ and a large majority of the seniors have announced that the follicular capillaries ran towards the periphery of the follicle and opened on the reticulum around it, but they did not pay attention to the special space or sinus above-mentioned. An experiment by $\mathrm{Ma} 11$ ('02) is something like the author's observations and arouses intesest in his. He employed asphalt-terpentine, which Hoy e r ('00) used at first, to elucidate the arterio-venous anastomosis 
in the spleen, and described that the materials, in all of these tests, were always immediately around the Malpighian follicles, showing that the openings at this point were very large and numerous. So constant was the extravasation found that it was out of the question to consider the openings around the follicles as artificial. As results of the plastoid casting, $\mathrm{Bl} \mathrm{e} \mathrm{ch} \mathrm{schmidt} \mathrm{stated,} \mathrm{the} \mathrm{red} \mathrm{pulp}$ had the venous plexus and another one enclosed with reticular cells, the latter being arteriell-injizierbar, which he called Arteriensinus.

Bases what the author would make a reference to the arterial sinusoid are as follows:-

The inside wall of the arterial sinusoid around the follicle is perfectly continuous to the capillaries in the germinal centre with endothelial cells, however, hard to recognize the cells at the contacting portions to the venous sinus. The morphological aspect of the arterial sinusoid differs from that of the venous sinus or the originals of the venous system even at first sight, though there are variations in species, especially on the corrosions injected into both the artery and the vein. Besides, the sinusoid shows its location, surrounding the follicle in globular shape similar to the shape of it.

By means of the various supporting experiments, the view that the sinusoid is not artificial, but is in existence normally, is intensified:-1) In dog, cat and cattle, the resin with very lower viscosity was injected so slowly into the artery until the colour of the resin is projected deeply on the surface of the spleen (part of the resin pours out of the vein). Such corrosions are like hollow balls and indistinguishable from the individual sinusoid. Following interpretation would be put on this result. Plenty of the resin injected one-sidedly into the artery collects in a definite region around the follicle, extravasates into the reticulum of the halo from the sinusoid and forms a hollow ball adhering to each other after the reticulum breaks. If the arterial sinusoid is nothing but a reticular mesh of the red pulp, the resin injected by such procedures may spread into the whole red pulp without confining it to the particular region of the follicle. 2) Although the injection is made reversely into the vein and then the artery, the resin through the artery is recognized in the particular zone of the follicle, after the sinus (reticular mesh in cat and pig) is already filled with the resin through the vein. The arterial sinusoid in the halo must not be filled with resin through the vein, namely, the splenic sinus does not exist in the halo (Fig. 1). 3) In dog, the resin injection was done into the artery after injecting a carbon-black suspension 
intravenously: The region of the carbon-black deposition coincides with that of the resin injection around the follicle (Fig. 10). As results of this experiment, the arterial sinusoid above-mentioned is different from the Arteriensinus having the reticular cells by $\mathrm{B} 1 \mathrm{ech}$ $\mathrm{schmidt}$.

It was considered by $\mathrm{O}$ no and his school that the follicular capillaries were very fine so that only blood plasma circulated, but $\mathrm{Na} \mathrm{kata} \mathrm{('54)} \mathrm{did} \mathrm{not} \mathrm{recognize} \mathrm{this} \mathrm{fact} \mathrm{by} \mathrm{his} \mathrm{transillumination} \mathrm{in}$ living subject. Judging from these results, it is safe to imagine that great quantities of blood pass through the follicular capillaries and reach at first the arterial sinusoid in the perimeter of the follicle and further pour into the venous originals.

It tries to discuss about branches of the penicillar artery come into in and around the follicle, that was stressed by $\mathrm{H} \mathrm{u} \mathrm{ec} \mathrm{k}, \mathrm{J}$ ä ger, $\mathrm{Qno}, \mathrm{T}$. I $\mathrm{mai}$ and $\mathrm{Kim} \mathrm{ma}$ etc. $\mathrm{MacNeal}$ et al. described this recurrence, called it centripetal arterial capillary, which opened on the red pulp around the follicle. Snook also reported the centripetal artery in man and cattle, especially many in the latter, and terminated in the marginal zone as well as the follicular capillaries. $\mathrm{Ono}$, in human embryo, I mai in cat respectively stated the same branch but they did not find Jäger's loop. Problems about the recurrent branch are two matters, that is, one being concerned in the construction of the follicular capillary plexus (already discussed) and the other opening on the red pulp or the sinus around the follicle. On the latter, author observed the view as the Snook's, in dog and rabbit after the cattle, very few or no in other species. Moreover, the artery has some variations according to the species, the recurring course is in the halo in rabbit, more perimeterical in dog, and in cattle and goat in the red pulp around the follicle, so the length of it is long. All these branches in any species pour into the arterial sinusoid of the halo, few of them (in cattle, goat and rabbit) anastomose with the follicular capillary plexus without $J$ ä g e r's loop. The follicular capillaries pour into the arterial sinusoid around the follicle and the centripetal artery also into this sinusoid from outside of the follicle, thereby it may. safely be said that a loop inserted the arterial sinusoid is existent.

A great number of works on the ellipsoid has been experienced morphologically and physiologically in various aspects, but its true form and character are not yet found. With Billroth (1856, 1861-2), Schweigger-Seidel. (1863), it was discovered and studied 
comparatively at first on birds and mammals. The studies have been made only on histological structures, and later surveyed on interrelation with that structures and permeability of the matters since materials were discharged from the ellipsoid experimentally.

Form of the ellipsoid is explained as fusiformal or cylindrical in general. Robins on ('25) described it pear-shaped and biconate or triconate in dog; Solnitzky ('37), small elongated cylindrical for the most in man and dog, large spherical or ovoid for the most in pig and cat. The observation in this thesis, is practically in accord with theirs, and the most appropriate figure may be suitable to be projectile or fusiform since the distal end of it points for the most, but in dog, cattle and goat spherical or ovoid, too.

On measurement of the ellipsoid, $\mathrm{S}$ n o ok described $195 \times 62 \mu$ in pig, $100 \times 86 \mu$ in cat, $80 \times 38 \mu$ in dog. The values by author's cast are larger than his, since the values include the portions of the periglumar mesh-spaces.

Whether arterial branch passing through the centre of the ellipsoid is arteriole or arterial capillary?:-Schweigger-Seider, Petersen ('31) argued it the capillary by his morphological studies. Solnitzky stated the vessel was not the artery at least, but it should be regarded as the sheathed capillary advanced by $\mathrm{Kle} \mathrm{m}$ perer ('38). Bannwarth (1891), Whit ing (1897) considered the ellipsoid as a contractile muscular organ, so was identified with the artery. But the ellipsoid is a condensation of the reticular tissue and lacking in an active contractile element, so it is impossible to be a true artery. On o, T. I m ai ('38, '40, '41, '47, '54) described from their embryological studies on the ellipsoid, that it was a spindle expansion of the arterial wall originated in embryonic adventitia accessoria, namely, undifferentiated vessels of the primordial arterial capillary. Accordingly, they named the ellipsoid Kapillar. enhülse, and the ellipsoidal artery Hülsenkapillaren. Os o go e ('54) once expressed his approval with them, still stated that the ellipsoid was not completed its differentiation to a capillary and was a special organon not applicable to whether artery or capillary. Author's opinion is that it would be suitable to regard it as a capillary, as results of the resin injection, that is:-1) The vessel is too fine to get name of an artery $(2.5-12 \mu, \mathrm{Kle} \mathrm{mperer} 15 \mu, \mathrm{S} \mathrm{n}$ o o k $10-14 \mu$, Maximow 6-8 $\mu$ ). 2) Even if the vessel is expanded to its maximum by viscosity and injection pressure, the inside wall of it is not so even as ordinary on the cast. 3) Being lacking in an active 
contractile element, as in the literatures, hence it would be named the vessel ellipsoidal central capillary.

Functions of the ellipsoid have been interpreted variously, and it is not too much to say they are still incomprehensible. It is, however, not considered the ellipsoid as an active contractile regulator of the blood stream. It is an undifferentiated type of the arterial wall or a reticular tissue that adventitia thickened partially, according to Schweigger-Seidel, Hoyer, Carlier (1895), Weidenreich, S ob ot ta ('14), Hueck, Jäger, Solnitzky, T. Imai, Ono etc., above all Solnitzky and Imai observed its fibrous construction in detail.

Followings are chief theories about the function (except the immunological) by seniors:-a) Theories of mechanical function: 1) Blood streaming regulation; abrupt narrowness of the central capillary suppresses temporarily the blood stream, advocated by Weidenreich, Neubert ('22), Oberniedermayr ('26), Herrath ('36) and Yoshida ('53). This is, however, unavailable nowadays from the strong permeability of the capillary wall. 2) Capillary protection; the ellipsoid itself acts as a buffer equipment for the rhythmical movement of the spleen, considered by Hoyer, Carlier and Riedel ('32). 3) Regurgitation proof; the ellipsoid was called one way valve by T ait and Cashin ('25), Rückflussventil by $\mathrm{He}$ ide $\mathrm{nh}$ a in ('28), and they stated that is acted as regurgitation proof valve, being consequent on compression of the ellipsoid under dilating of the splenic pulp. Weidenreich, Mollier ('11), Neubert, MacNeal et al., Mackenzie et al. ('41), have the nearly same opinion. With T. I $\mathrm{ma}$ i, when the ellipsoid works itself, a role as a valve is discharged by being pressed the periglumar mesh-space. b) Theories of biological function: 1) Developmental centrum; the ellipsoid was ever considered as a developmental womb of the splenic vessels and pulp; with Bannwarth, Greschik ('15), Sta emmler ('25). But nowadays it is not an agreeable theory. 2) Blood filtration; it is looked upon as most important at present. S chweig ger-Seid el stated at first, coloured matters stayed at the ellipsoid after their injecting experiments. Later, seniors who studied on the ellipsoid always employed some injecting experiments and described the fact that the wall of the ellipsoidal central capillary had a high permeability. Greschik, Hoyer, Staemmler, Mills ('26), Hartma n $\mathrm{n}$ ('30) and S. I ma i ('55) stated, this phenomenon was attributable to preformed stigmata on the wall of the central capillary. And 
Hueck, Solnitzky, Tei ('37), T. Imai, Kihara ('50), Osogoe had an opinion that the wall had no preformed stigmata, and blood plasma was filtrated only. Since erythrocytes (by O s o goe), blood corpuscle of hen and kala-azar (by $\mathrm{T}$. I m a i) passed through the wall of it, they stated concrete elements of the blood (especially erythrocytes) might be oozed out, and on the transillumination placed their hope, M a c ken $\mathrm{z}$ i e et al. stated, stigmata should be existent on the wall though it was observed to be intact in cat.

Author's observations are that, the resin reaches the periglumar mesh-spaces from the wall of the central capillary, via some routes of the ellipsoid in every animal (except rabbit). Casts of it have regular form injected into tissue-spaces (or sometimes looking like lateral branches of the central capillary). That is, this appearance is not to spread diffusely into the reticular mesh within the ellipsoid, is confirmed. Circumspect consideration is required about that strongly permeable wall of the central capillary in physiological might be broken by injection pressure and viscosity of the resin, and these aspects might be artificial. But, the pressure below $500 \mathrm{mmHg}$ at injection-syringe ought to decline pretty sharply at the ellipsoid, and if the casts in the ellipsoid were produced by destruction of the wall, it may be not obtained casts of such regular spaces constantly, and the resin should turn into irregular lumps, not arriving at peripheries behind the ellipsoid. Mü $11 \mathrm{er}$ (1865), B an nwarth saw coloured matters deposited in the ellipsoid, but concluded that they were no more than extravasation. : Then, if the author's observation is extravasation, it may be not caught the radiating routes from the central capillary, but the cast must be simply massed. While, results of coloured matter injections by seniors and the same vital injections are in accord with the resin injection after the carbon-black injection intravenously by author. Snook, Ohtsuka ('55) stated lateral branches were derived from the central capillary and opened on the red pulp around the ellipsoid. In author's specimens, some of the regular tissue spaces appear as the above-mentioned lateral branches, but it is unable to assert them the lateral branches since endothelial cells are unrecognizable.

In the last analysis, author considers, the ellipsoid is a worthy filter, that has blood filtering function and which gets to filter through concrete blood elements under a certain condition (I mai, Snook and $\mathrm{Osogoe}$ ), not to mention the blood plasma ( $\mathrm{H} \mathrm{u} \mathrm{eck}$ ). There are many works that reported coloured matters deposited in the 
ellipsoid, but none demonstrated the routes in it from wall of the central capillary. The reason why the author could demonstrate the routes is due to unmixiableness of the resin with tissue fluid. While, it is unsafe to give any conclusion about the mechanical function of the ellipsoid only in conjecture or imagination, provided that it is recognized any obvious facts morphologically.

Branching features of the penici lar artery, as it has been known, are so-called penicilli (by some seniors slightly separate one another), but those observed the aspect panoramically or comparatively are few. In author's observation these aspects are, as already mentioned, the penicillar type, its slightly separate, and octopus type as if tentacles of an octopus in large angle, which is scarcely related to the penicillar appearance. These various features have many variations in species as well as individual. Above all, octopus type branching in cattle, and fan-shaped type (octopus in a plane) in goat and rabbit are remarkable respectively.

More or less tortuosities of the whole penicillar arteries are recognized in every animal. In cat strong meanderings are seen in the whole penicillar arteries, the most before the ellipsoid, weaken behind it; in pig a little or none behind the ellipsoid; in order of goat, cattle, dog and man the tortuosities are diminished. It is uncomprehensible what signification the strength of the tortuosities has, or whether any pathological changes or not.

About direct anastomosing between the arterial terminals and the venous system, a majority of scholars has been insisting on the open circulation route, some on the close circulation and also some compromise of them. Although it might be inadequate, that the author's results of the resin injection are compared and discussed with works of seniors on these items, it would be conceived on the arterial terminals quoting some seniors. Gol z (1893), T h o ma ('24) noticed in dog, the arterial capillary terminals opened on the splenic pulp with ampullae on their ends. Mall called them Th o ma's ampullae. $\mathrm{B}$ ra us ovale Endkammer der Arterie and many scholars described them in some mammals. Mackenzie et al. recognized the ampullae by transillumination in mouse and cat, and described wall of them to look like porosity though appeared intactly. S nook found many of elliptical, spherical and branched shaped ampullae in dog. In this paper, it is described the terminals amplified as clubs in dog and pig, but in these species as well as the others blind terminals without ampullae are seen large in number. These terminals neither leave 
open on the red pulp nor directly connect with venous branches. Even if the injecting amount increases, the form of the ampullae does not change and its length not grow. In some of these experiments, the resin effused from the terminals mixes with that through the vein, but anyone shaped like specific geordnete Bahn by $\mathrm{Hu}$ e ck was not observed. The matter that should be called in question may be the appearing-frequency of direct arterio-venous anastomoses, the close route. In every species, the number of direct connections is lesser than that of arterial terminal capillaries, but considerably many in dog, goat, rabbit and man.

The great problem of the venous system consists in its originals, namely, the existence of the splenic sinus and morphological differences in species.

In literatures, the originals are grouped into a type being not much of the sinus non-anastomosed and a type of so-called sinus anastomosed richly according to species. S chu m a cher ('00), B il$1 \mathrm{roth}$ classified them into scarce anastomosing one (horse, pig and cattle) and rich anastomosing one (cavernous plexus, man and rabbit), Hoye $r$ added dog as their intermediary type and to the latter group rodentia, while he also classified into those that have venous capillary of irregular reticular wall (pig and goat) and those of regular wall (dog, ape and man). Later, S nook assorted into sinusal type that had circular fiber (rat, guinea-pig, rabbit, dog, man, skunk, squirrel) and non-sinusal type lacking in the fiber (mouse, pig, cat, cattle, mole, weasel, bat, horse). T. I $\mathrm{mai}, \mathrm{Ohtsuka}, \mathrm{Snook}$ endeavoured to find some interrelation between the differences of the developmental stage of the sinus and the general structure, especially the developmental stage of the ellipsoid. They stated that those which lacked the ellipsoid had well developed sinus while those had the ellipsoid were lacking in a true sinus but only one in stage of so-called primordial vein by Robins on ('26, '30), S nook, or even the sinus existed poor (dog), but unusually in man well developed rich anasto. mosing sinus as well as in guinea-pig. In author's resin injection, it is obtainable to be corrosions with lumen of the splenic venous system expanded to its maximum by virtue of properties of the resin, in other words, the studies are on the venous system filled up with blood. To put the animals in order of the developmental stage of the sinus; rabbit, man, dog, cattle, goat and pig. About the cat's the author was much interested in observation as the seniors always disputed. Bannwarth called venous originals kurzer Venenursprung, 
kapilläre Ansatzröhrehen by $\mathrm{Riedel}$, primordial venous branch by Neubert, Robinson, Mackenzie and T. Imai. In this paper, knobs or buds, like portions on wall of the originals, are found on the corrosions, but no account about that may be given. These projecting portions seem to be identified with parts injected into the stigmata of sinusal wall (porosious) as disputed up to this day. If they were actual, they ought to be found in every species, but such a view is obtainable only in cat. Therefore, it is invited consideration that if the projecting portions are grown they may turn into anastomosing sinuses, vice versa may degenerate into poor branchings, primordial veins as some siniors said (cattle, pig and goat). Those in cat may be faintly developed one of primordial vein in cattle, pig and goat. The most developed originals are in man and dog next to in rabbit, and maximum surface area of them is in rabbit and dog after in man, and these lengths of whole venous system in the spleen are large. Accordingly, this fact might be related to the frequency of the direct arterio-venous anastomoses. The matter that should be reconsidered is that, when the injection into the vein increases it is not gotten regular casts appeared as vessels, in the species whose venous originals are undergrown, but only resin lumps effused into the splenic pulp from venous originals. Consequently, it is able to imagine that the blood easily streams in the venous originals through their wall in these species, but this does not agree with observation by $\mathrm{Nakata}$. Sinuses in various phases with transillumination, experienced by $\mathrm{Kn}$ is ely ('36), Peck and $\mathrm{Hörr}$ ('51), Mackenzie et al, $\mathrm{Nak}$ a $\mathrm{ta}$, are not recognizable.

Whether the splenic sinus or the pulp commits blood reservoir, one of functions of the spleen, has been disputed. As a result of author's observation, it is considered that the sinus acts as the reservoir in the species whose sinus developed while the splenic pulp also in those sinus undergrown.

\section{Conclusion}

1. Acrylic resin injection is performed into the splenic artery and vein in dog, cat, cattle, pig, rabbit and human subject, and studied cubically on their corrosion specimens and resin injected sections.

2. Arteries covered with lymphatic tissue are differentiated lymph-sheathed artery from follicular artery.

3. Arterial branches which supply the follicle, though varying 
with the species, are chiefly the ones directly or via stems diverged from the follicular artery, and besides branches out of the lymph. sheathed artery or sometimes recurrences of the penicillar artery.

4. In the lymphatic sheath as well as in the follicle, the capilary plexus is recognizable, especially more distinctly in goat and pig.

5. Follicular capillary plexus is dense mesh and each capillary fine $(3-20 \mu)$. To arrange in order of density; rabbit $>$ dog $>$ cattle $>$ human subject $>$ goat $>$ pig $>$ cat.

6. In rabbit some of capillaries in the supermost layer of the follicle take tangential course against surface of the follicle.

7. In every species the capillary plexuses in the lymphatic sheath and the follicle open on specific sinusoids around them. It is carried a suggestion of that great amount of the blood in the follicle pours into the very sinusoids through the capillary plexueses. The sinusoids are able to be injected only from the arterial side, so they would be named arterial sinusoids.

8. Arterial sinusoids locate in the mantle and the halo of the lymphatic sheath and the follicle. The individual sinusoid is in shape of small drop-like chamberlet (short spur in cattle, stellate in rabbit), and which congregates one another. Further, these sinusoids connect with splenic sinuses around them.

9. Branch, recurs to the follicle, of the penicillar artery is few, but many in cattle, dog and rabbit. Some of the recurrents. open on the arterial sinusoid,

10. Arterial vessel passing through in axis of the ellipsoid should be called central capillary, estimating from its thickness, form and permeability of the wand.

11. In the ellipsoid radiating tissue spaces $(1.3-7 \mu$ in thickness) from wall of the central capillary are recognized, some of which look like lateral branches. Morphological aspects of these species could be demonstrated by resin injection. These spaces are continuous to the periglumar mesh-spaces. Therefore, they suggest that stigmata situate on the wall of the central capillary, and the blood is filtrated from them in a certain physiological condition.

12. Branching aspects of the penicillar artery appear from penicillar type to octopus' tentacles (in large angle).

13. Of direct connection of the arterial terminal capillary and the venous system, there are variations in species:- Many of direct connection (rabbit and man), both. blind terminals and connection (dog and goat) and none of direct connection (cattle, pig and cat). 
Many of blind terminals are seen as Tho ma's ampullae in dog and pig, but none in other animals.

14. Splenic venous originals could be cubically demonstrated and entirely observed comparatively. The most developed anastomosing sinus is in order of rabbit, man and dog; thick venous original branch, not looking like a sinus (primordial vein) in cat, cattle, goat and pig. Especially in cat, isolated or congregated knobs or buds-like projections are observed on venous originals. It is suggested they are still in the unfinished developmental stage to the sinus, and possible to situate in average of seven species studied.

In conclusion the authorwishes to express his deep-felt thanks to his respected instructor Professor Y. T a $\mathrm{n} \mathrm{g} \mathrm{u} \mathrm{chi} \mathrm{for} \mathrm{guidance} \mathrm{and}$ encouragement shown to him, besides is much indebted to Dr. S. $\mathrm{T}$ a n ig u chi, Jr. for procurement of human spleen, and to Dr. S. T a jiri, D.D.S. who assisted the author in various experiments.

Part of this research was made possible by favour of the Grantin-aid for Scientific Research by the Ministry of Education, for which the author expresses his gratitude.

\section{LITERATURES CITED}

1) Alt schul, R. \& Hummason, F. A.; 1947. Minimar vascular injection of the spleen. Anat. Rec., 97, 259.

2) Andrew, W.; 1946. Age changes in the vascular architecture and cell content in the spleens of $100 \mathrm{Wistar}$ Institute rats, including comparisons with human material. Am. J. Anat, 79, 1.

3) Bannwarth, J.; 1891. Untersuchungen aber die Milz. Arch. mikr. Anat., 38, 345.

4) Billroth, T.; 1856. Beitrăge zur vergleichenden Histologie der Milz. Arch. Anat. Physiol. u. wiss. Med., 88. (by Scheweigger-Seidel)

5) Dit to; 1861. Zur normalen und pathologischen Anatomie der menschlichen Milz. Arch. path. Anat., 20, 409.

6) Dit t o; 1862. Ibid., 23. 457.

7) Blechschmidt, A; 1938. Vorweisungen von Mikrokorrosionen zur Frage der Architektur der roten Milzpulpa. Anat. Anz. Ergănzungsheft zum Bd. 85, 252.

8) Bra u s, H.; 1924. Anatomie des Menschen. II, Berlin, 580.

9) Carlier, E. W.; 1895. Note on the minute structure of the reticulum in the cat's slpeen. J. Anat. \& Physiol, 29, 479.

10) Golz, S.; 1893. Untersuchungen über die Blutgefässe der Milz. (by Thoma)

11) Greschik, E.; 1915. Ueber den Bau der Milz einiger vogel mit besonderer Berïchsichtigung der .Schweigger-Seidelschen Kapillarhülsen. (by Hoyer)

12) Hartmann, A.; 1930. Mollendorff's Hb. d. mikr. Anat. d. Mensth. VI-1, 397. 
13) Hei den hain, R. P.; 1928, Ueber die Kapillarventile der Mila. Münch med. Wochenschr, 75, 381 .

14) Herrath, W.; 1936. Bau und Funktion der Mïlz. Z. Zellforsch. mikr. Anat., 23, 375.

15) Hoyer, H.; 1893. Ueber den Milz. (by Mall)

16). Dit t 0; 1950. Zur Histologie der kapillaren Venen in der Milz. Anat. Anz., 17, 490.

17) H u e ck, W.; 1928. Lie normale menschliche Milz als Bluttehälter. Verhandl. deutsch. path. Gessellsch., 23, 6.

18) I $\mathrm{ma} i$, S.; 1955. A new information on the structure of the sheathed artery. Kaibo. Z., Abstract of 60th Jap. Ant. Session, 69.--in Japanse.

19) I m a i, T.; 1938. Splenic vasculature, especially vascular arrangement of the Malpighian bodies, of the cat's spleen. Fukuoka Acta med., 31, 106.-in Japanese.

20) Ditto; 1938. Studies on the spleen infected with Kala-azar, especially its capillary ellipsoid. J. Soc. path. Jap., 28, 152.-in Japanese.

21) D i t o; 1940. Function and structure of the ellipsoid of the cat's spleen. Fukuoka Acta med., 33, 961.-in Japanese.

22) Dit to; 1941. Relationship between histological appearance of Schweigger-Seidel sheath and general structure of spleen. J. Soc. Path Jap., 31, 231.-in Japnese.

23) Dit to; 1947. Reticular framework of the Scheweigger-Seidel sheath of the splesn. Fukuoka Acta. med., 38, 1.-in Japanese.

24) Ditto; 1954. Problems on the vsacular ellipsoid of the spleen, with special reference to its morphological findings. Sympisium on hematology, 7, 60.-in Japanse. .

25) J ăg e r, E.; 1929, Die Gefăssversorgung đer Malpighischen Körperchen in der Milz. Z. Zellforsch. mikr. Anat., 8, 578.

26) Kiha ra, T.; 1950. Extravaskuläre Saftbahnsystem. Simposium on hematolozy. 3, 118.-in Japanese.

27) Kim u ra, S.; 1952. Vascular arrangement of the Mialpighian bodies of the spleen. J. Kyu. Hem. Soc., 2, 11.--in Japaness.

28) Klemperer, P.; 1998. - The spleen. Downey's handbook of hematology, III, N. Y., 1591.

29) Kn is ely, M.H.; 1936. Spleen studies I. Anat. Rec., 65, 23.

30) Kolliker, A.; 1849. (by Kimura)

31) Kyber, K.; 1870. Ueber die Milz dez Menschen und einiger Säugetiere. Arch. mikr. Anat., 6, 540.

32) Mackenzie, D.W. Jr., Whipple, A. O. \& Wintersteiner, M. P"; 1941. Studies on the microscopic anatomy \& physiology of living transilluminated mammalian spleen. Am. J. Anat., 68, 397.

33) MacNeal, W., Otani, S. \& Patterson, M. B.; 1927. The finer vascular channels of the spleen. Am. J. Path., 3, 111.

34) Ma 1, P.F.; 1902. On the circulation through the pulp of the dog's spleen. Am. J. Anat., 2, 315.

35) Maxinow, A. A.; 1953. Textbook of histolozy. Philadelphia, 270.

36) Mills, E.S.; 1926. The vascular arrangement of the mammalian's spleen. Quart. J. Anat. a. Physiol., 16, 301.

37) Mollier, S.; 1911. Ueber den Bau der kapillaren Milzvenen (Milzsinus). Arch, mikr. Anat., 76, 608.

38) Müller, W.; 1865. Ueber den feineren Bau der Milz. (by Mollendorff) 
39) Na kat a, K.; 1954. Intravital observations of the splenic circulation. Symposium on hematology, 7, 36. - in Japanese.

40.) Neubert, K.; 1922. Der Uebergang der Arteriellen in die venöse Blutbahn bei der Milz. Zeit. Anat. u. Entwick!., 66, 424.

41) Nisimaru, Y. \& Steggerda, F.R.; 1932. Observations on the structure and function of certain blood vessels of the spleen. J. Physiol., 74, 327.

42) Oberniedermayr, A.; 1926. Der Weg des Blutes durch die Hundmilz. Kreislaufforsch., 3, 476.

43) O no, K.; 1930. Untersuchung über die Entwicklung des meschlichen Milz. Z. Zellforsch. mikr. Anat., 10, 573.

44) Os og o e, B.; 1951. Phylogenesis of the spleen. Symposium on hematology $7,1$. - in Japaness.

45) O hts u ka. Y.; 1955. Relationship betwen histological appearance of SchweíggerSeidel sheath and general structrue of spleen. J. Kyu. Hem. Soc., 5, 104. - in Japanese.

46) Peck, H.M. \& Hörr, N.L.; 1951. The intermediary circulation in the red pulp of the mouse spleen. Anat. Rec., 109, 447.

47) Petersen, H.; 1931. Die Milz. (by Solnitzky)

48) Robins on, W. L.; 1925. The vascular mechenism of the spleen. Am. J. Path, 2, 341.

49) Ditt o.; 1930. The venous drainage of the cat spleen. Am. J. Path, 6, 19.

50) Riedel, H.; 1932. Das Gefăsssystem der Katzenmilz. Z. Zellforsch. mikr. Anat., $15,459$.

51) Röhlich. K.; 1933. Struktur und Blutgefăssversorgung der Keimzentren. Anat. Anz., 76, 215.

52) Schumacher, S. ; 1900. Das elastische Gewebe der Milz. Arch mikr. Anat., $55,151$.

53) Schwe igg er-S e idel, F. ; 1863. Untersuchung über die Milz. Virchow's Arch. Path. u. Physiol., 27, 460.

54) S nook, T. ; 1950. A comparative study of the vascular arrangements in mammalian spleen. A.m. J. Anat. , 87, 31.

55) S ob ot ta, J.; 1914. Hb. der Anatomie., III, Jena. 281.

56) Soln it $z \mathrm{ky}, 0$; 1937. The Schweigger-Seidel sheath (ellipsoid) of the spleen. Anat. Rec., 69, 55.

57) St a e m m l er, M. ; 1925. Die Bedeutung der Schweigger-Seidelschen Kapillarhülsen der Milz. Virchow's Arch. Path. u. Physiol., 255, 585.

58) Tait, J. \& Cashin, M.F.; 1925. Some points concerning the structure and function of the spleen. Quart. J. Exp. Physiol,. 15, 421.

59) Taniguchi, Y., Ohta, Y. \& Tajiri, S. ; 1952. New improved mathod for injection of acrylic resin. Okajimas Fol. Anat. Jap., 24, 259.

60) Taniguchi, Y., Ohta, Y., Tajiri, S., Okano, H. \& Hanai, H.; 1955. Supplement to new improved method for injection of acrylic resin. Okajimas Fol. Anat. Jap., 27, 401.

61) T e i, J. ; 1937. Communication among intercellular spaces, lymphatic sinuses and blood vessels within parenchyma of lymphatic node. Nippon Geka Hoken, 14, 935. -in Japanese.

62) Thoma, R. ; 1924. Der normale Blutstrom und die venöse Stauung in der Milz. Arch. Path. Anat., 249, 100.

69) Weidenreich, F.; 1901. Das Gefässeystem der menschlichen Mile. Arch. 
mikr. Anat. u. Entwickl., 58, 247.

64) Whit ing, A.J.; 1897. The comparative histology and physiology of the spleen. Trans. Roy. Soc. Edinbs., 38, 253.

65) Yoshida, Y.; 1953. On the fine structures and its development in the pig's spleen. Kaibo. Z., Abstract of 58th Jap. Ant. Session, 43. -in Japanese.

\section{Explanation of Figures}

Plate I.

Fig. 1. Rabbit, section. Two follicles (n), arterial sinusoid (as) surrounding them and splenic sinuses $(s) . \quad \times 70$.

Fig. 2. Man, cast. Direct connsction batween arterial terminal capillary (white-reddish) and sinus (blue). Ends of sinuses are shown expanded, so appear glanular. $\times 75$.

Fig. 3. Dog, section. Follicular artery (eccentric), capillaries from it and a branch, distributes into the follicle $(\downarrow)$, diverged from the lymph-sheathed artery before the follicle. Recurrent branch $(\rightarrow)$ and arterial sinusoids (as, cricoid aspect according with outline of the follicle). $\times 62$.

Fig. 4. Dog, cast. Lymph-sheathed artery, follicular arteries (eccentric), stems supply the capillary plexuses in them. Almost parts of arterial sinusoids (dotted line) around the sheath add the follicle are removed but downwards. $\times 25$.

Fig. 5. Dog, cast. Capiliaries dire:tly diverged from the follicular artery, and their meshes. $\times 95$.

Fig. 6. Dog, cast. A stem ( $\downarrow$ ) out of the follicular artery (eccentric), and capillaries from the stem. White matters appearing as congregations of water drops at left show arterial sinusoids, while part of them at right is removed. $\times 35$.

Fig. 7. Dog, cast. Branches ( $\rightarrow$, from left to right) distribute into the follicle (dotted line), diverged from the lymph-sheathed artery at the proximal portion of the follicle (arterial sinusoids are removed). $\times 27$.

Plate II.

Fig. 8. Dog, section. A recurrent branch of the penicillar artery. Its terminal opens on arterial sinusoids (as) around the lymphatic sheath and further the sinusoids connect with the sinuses (s). $\times 117$.

Fig 9. Dog, Section. Stained with H-E. Each one of arterial sinusoids in the halo of the follicle (at upper right). $\times 330$.

Fig. 10. Dog, section. Resin injection after injecting carbon-black intravenously. The resin is injected into the carbon-black depositions around the follicle $(n)$ and the same aspects show in several ellipsoids $(x) . \quad \times 95$.

Fig. 11. Dog, section. Terminals $(\downarrow)$ of the penicillar arteries open on the arterial sinusoids (as) around the follicle. Resin injected views in ellipsoid $(x)$, and sinus (s). $\times 66$.

Fig. 12. Dog, cast. Surface view about one of the congregations of the arterial sinusoids aronud the follicle. Two thick sinuses (black) connect with the sinusoids $(\rightarrow) . \quad \times 43$.

Fig. 13. Dog, section. Direct connection $(\downarrow)$ between the arterial terminal capillaries and the sinuses (s), and $\mathrm{Th}$ om a's ampullae $(x) . \quad \times 236$.

Fig. 14. Dog, section. Two of the imperfect injected ellipsoids, showing routes from wall of the central capillary into ellipsoidal tissue. $\times 254$. 
Fig. 15. Dog, section. Four ellipsoids in shape of projectiles. $\times 127$.

Fig.16. Dog, cast. Two ellipsoids. One at right is globular ellipsoid. Small drops and short spurs are casts of the tissue spaces or the periglumar mesh-spaces, and Thom a's ampulla $(\leftarrow) . \quad \times 105$.

Fig. 17. Dog, section. The same specimen with of Fig. 10. Ellipsoid. Wall of the central capillary is uneven, and routes from it to the periglumar mesh-spaces (black dotts are carbon-black). $\times 350$.

Plate III.

Fig. 18. Dog, section. Two $\mathrm{Th}$ o $\mathrm{m}$ a's ampullae and three ellipsoids $(x) . \times 55$.

Fig. 19. Cat, cast. Branching features of the penicillar arteries and their tortuosity. Casts of ellipsoids at right and upper left. $\times 50$.

Fig. 20. Cat, section. Follicular artery (severely eccentric), stems out of it to distribute into follicle and coarse plexus. Arterial sinusoids (as) connect with venous branches $(\rightarrow)$. $\times 86$.

Fig. 21. Doz, section. The same specimen with of fig. 17. Transsaction of an ellipsoid. Resin injected routes from wall of the central capillary to periglumar mesh-spaces. $\times 400$.

Fig. 22. Cat, section. Two ellipsoids. Central capillary $\rightarrow$ tissue spaces (or lateral branches?) in ellipsoids $\rightarrow$ periglumar mesh-spaces. $\times 68$.

Fig. 23. Cat, section Arterial sinusoids around the follicle, each of them appears as short spurs. $\times 220$.

Fig. 24. Cattle, cast. Two or three lymph-sheathed arteries $(\uparrow)$ or follicular arteries $(\uparrow)$ run abreast in a sheath or a follicle (dotted line). Capillary plexus directly diverged from the follicular artery in the middle, the mesh at left is out of fine recurrent arteries $(\rightarrow) . \quad \times 15$.

Fig. 25. Cattle, cast. Arterial sinusoids around the follicle. Branchings in penicillar type and recurrent branches. $\times 28$.

Fig. 26. Goat, cast. Part of arterial sinusoids (as) in the middle (dotted line), and a little saparate penicillar branchings. $\times 43$.

Fig. 27. Cat, cast. Knob-like projections (or lateral branches?) on wall of the central capillary, removing the resin in the ellipsoid and its zigzag course $(\uparrow)$. Casts of the periglumar mesh-spaces at the bottom and left. $\times 180$.

Plate IV.

Fig. 28. Cattle, cast. Arterial terminal capillaries seem to serve as vasa vasorum of a venous branch $(s) . \times 52$.

Fig. 29. Cattle cast. Octopus type branching of the penicillar arteries ( $\backslash$ branching point) and arterial sinusoids around the follicle (as). $\times 34$.

Fig. 30. Goat, section. A long arterial terminal capillary connects with venous branch $(\mathrm{s})$, black dotts are the resin into the arterial side. $\times 318$.

Fig. 31. Goat, section. A branch diverged from a follicular artery (fa) pours directly into arterial sinusoids (as). $\times 230$.

Fig. 32. Goat, section. Three lymph-sheathed arteries running abreast in a sheath and they divide into two follicular arteries still being parallel each other (fa). Black dotts are arterial sinusoids around the sheath and the follicle $\times 26$.

Fig. 33. Goat, cast. Lymph-sheathed arteries (slight meandering), follicular arteries and fan-shaped (or unfolded petals) branching of the penicillar arteries. $\times 6$.

Fig. 34. Pig, cast. Branching aspects of the penicillar arteries, four ellipsoids and 
spiral passing of the arteries before ellipgoids. $\times 80$.

Fig. 35. Pig, cast. Ellipsoid in shape of projectile is dissected. Central capillary in zigzag course, spine-like tissue spaces and cast3 of periglumar mesh-spaces in the bottom. $\times 310$.

Fig. 36. Pig, cast. Spiral passing of penicillar arteries. Ellipsoid in shape of morula. like projectile and a stout tissue space $(\rightarrow$, lateral branch?) from the central capillary at the distal end. $\times 110$.

Fig. 37. Pig, cast. Elongated ovoid ellipsoid (part of tissue spaces is dissected out). Central capillary in zigzag course, and spine or short spur-like tissue spaces. Casts of periglumar mesh-spaces at right. Arterial terminal capillary forms an ampulla at left. $\times 210$.

Fig. 38. Pig, cast. Part of an ellipsoid. Short spur-like (or lateral branches?) tissue spaces and casts of periglumar tissue spaces $(\uparrow \downarrow) . \times 330$.

Plate V.

Fig. 39. Pig, cast. Twin ellipsoids (adhering each other at the proximal ends). $\times 390$.

Fig. 40. Pig, section. Routes in an ellipsoid, from wall of the central capillary to periglumar mesh-spaces at left via tissue spaces. $\times 220$.

Fig. 41. Rabbit, cast. Follicular artery $(\lambda$, eccentric) and follicular capillary plexas (arterial sinusoids around the follicle are removed). $\times 36$.

Fig. 42. Rabbit, section. Lymph-sheathed arteries, follicular arteries, stems from them and arterial sinusoids around the follicles (black). $\times 80$.

Fig. 43. Pig, section of cast. Spine-like tissue spaces (or lateral branches?) in ellipsoid from wall of the central capillary. $\times 680$.

Fig. 44. Rabbit, section. Tangential capillaries $(\rightarrow)$ through the halo of the arterial sinusoids (as). $\times 320$.

Fig. 45. Rabbit, section. Sinuses (s), arterial sinusoids (as, stellate and polygon-like. The halo is thick in rabbit, $\uparrow$ ). Tangential follicular capillaries $\rightarrow$ arterial sinusoids $\rightarrow(\uparrow, \rightarrow)$ sinuses $(s) . \quad \times 300$.

Fig. 46. Rabbit, section. Arterial terminal capillaries directly connect with sinuses $(\rightarrow, \downarrow) . \times 360$.

Fig. 47. Rabbit, section. Tangential follicular capillaries in two layers $\rightarrow$ arterial sinusoids (as, stellate and polygon-like) $\rightarrow(\downarrow \uparrow)$ sinuses. $\times 300$.

\section{Plate VI.}

Fig. 48. Man, cast. Capillaries from stems out of the follicular artery $(\leftarrow)$ and ones directly out of it, and their mesh. Capillaries open on arterial sinusoids at left ( $\downarrow) . \times 100$.

Fig. 49. Man, cast. Follicular capillaries open on arterial sinusoids. $\times 110$.

Figs. 50, 51. Dog, cast. Cylindrical sinuses. $\times 84, \times 50$.

Figs. 52, 54, 57. Cat, cast. Venous originals curve in an arc form. Knob or bud-like projections are seen on the originals. $\times 70, \times 100, \times 110$.

Fig. 53. Pig, cast. Hacked-like venous originals. $\times 20$.

Figs. 56, 59. Cattle, cast. Coarse and long rod-like venous originals. $\times 23, \times 20$.

Figs. 55, 58. Rabbit, cast. Well developed sinuses. Ends of each one show expanded, compressed or forked. $\times 80, \times 60$.

Figs. 60,61, 62. Man, cast. Well develeped sinuses. Expanding. compressing or forking on ends of each one of them are more remarkable than in rabbit. $\times 50$, $\times 40, \times 75$. 

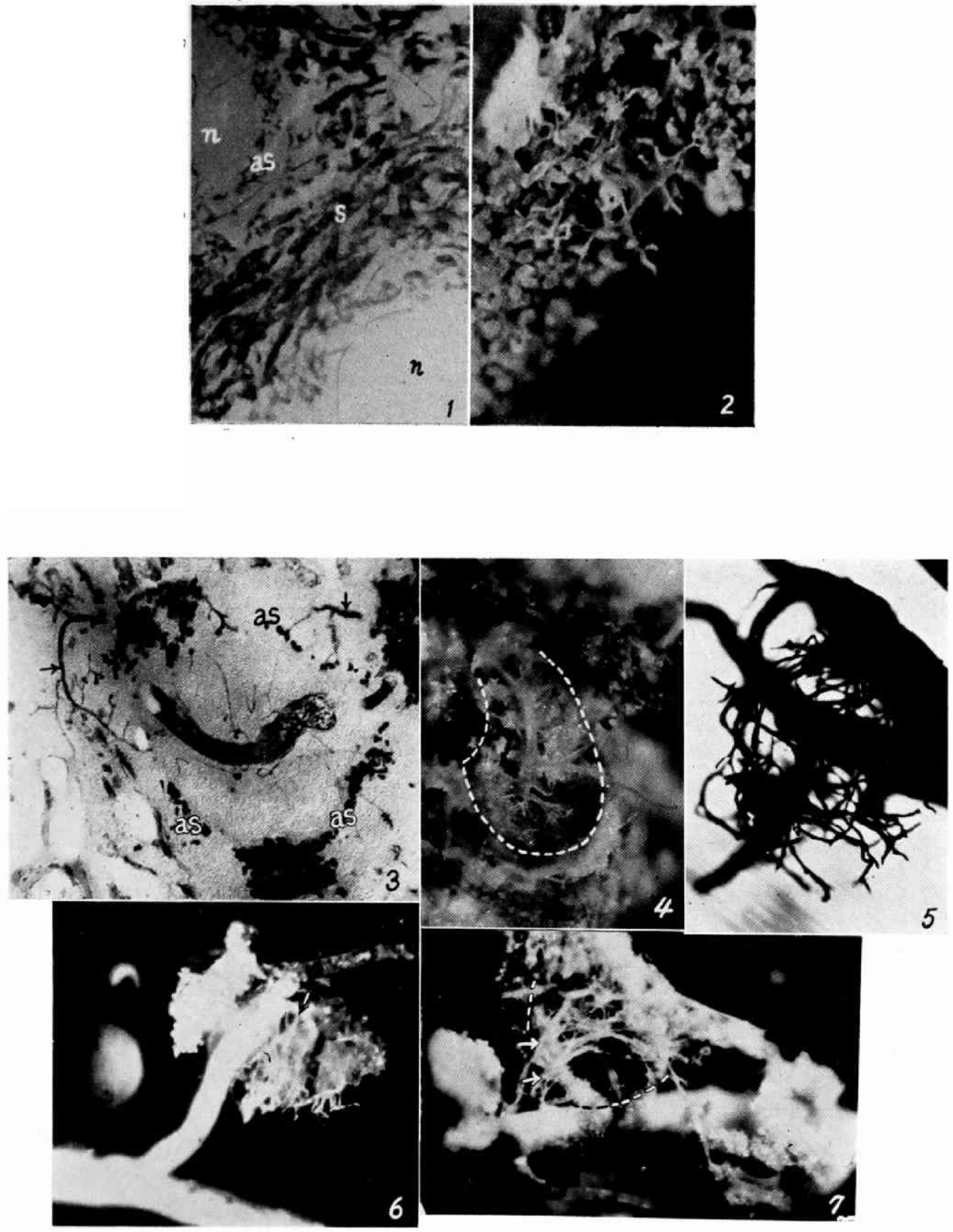


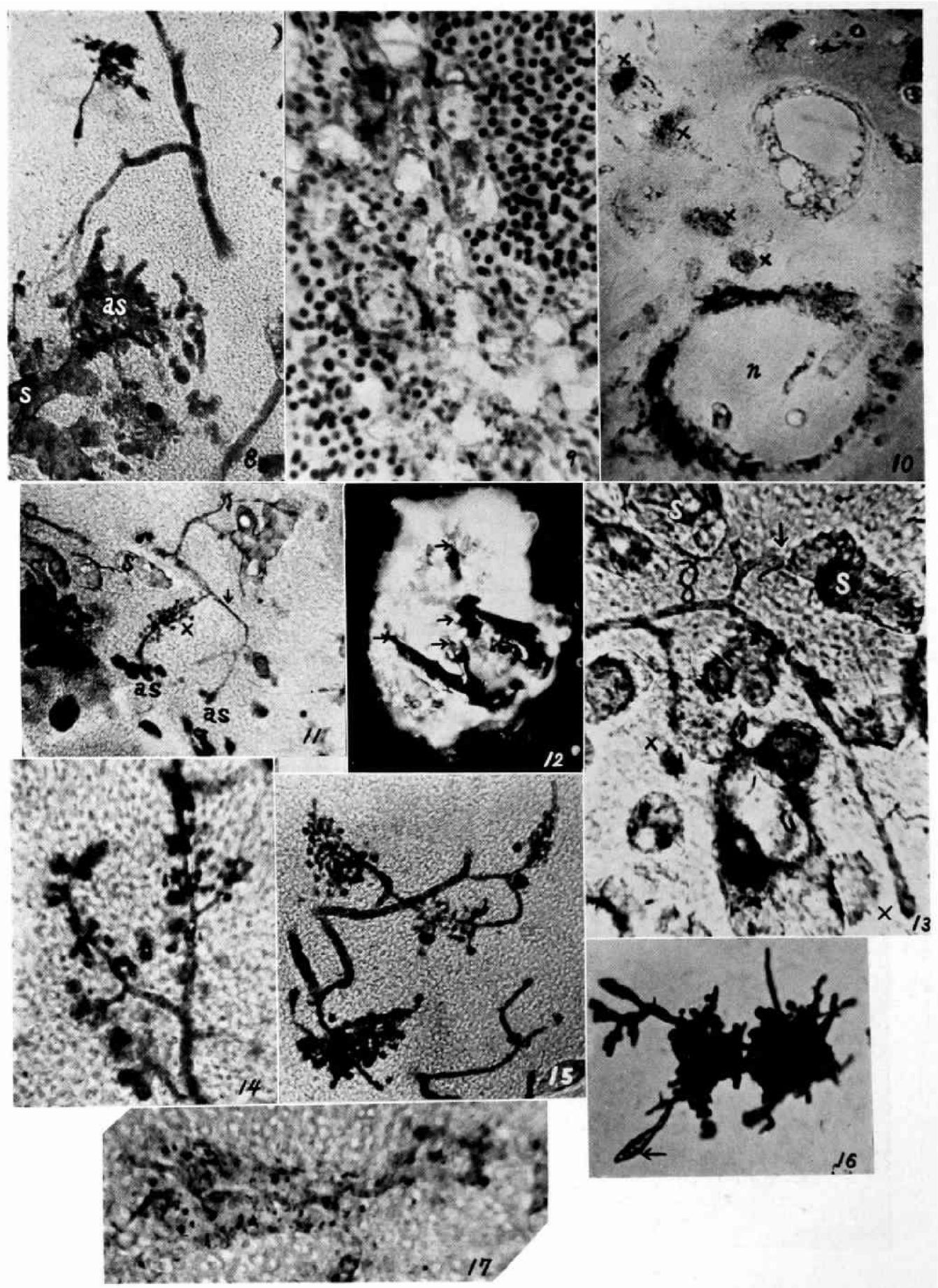




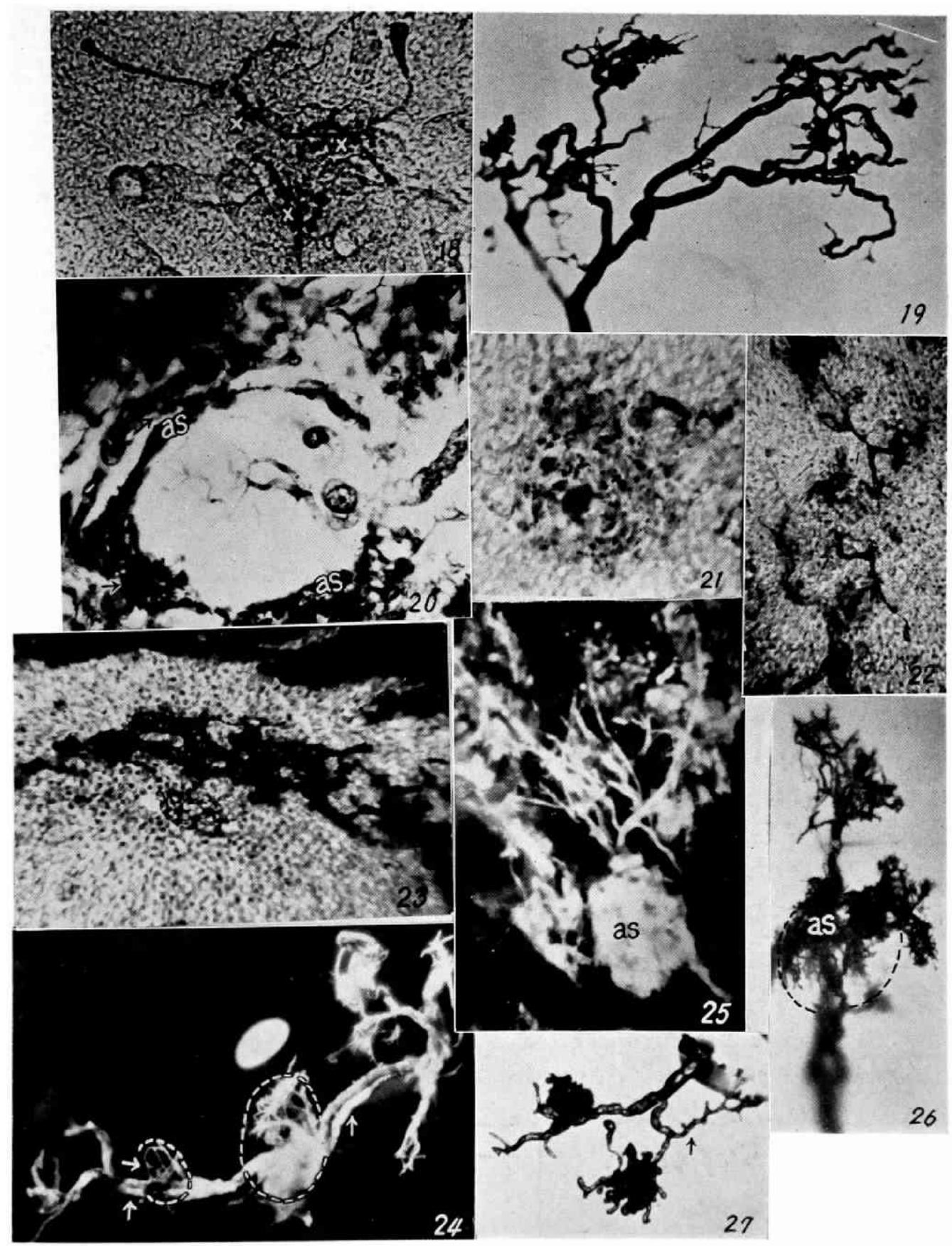




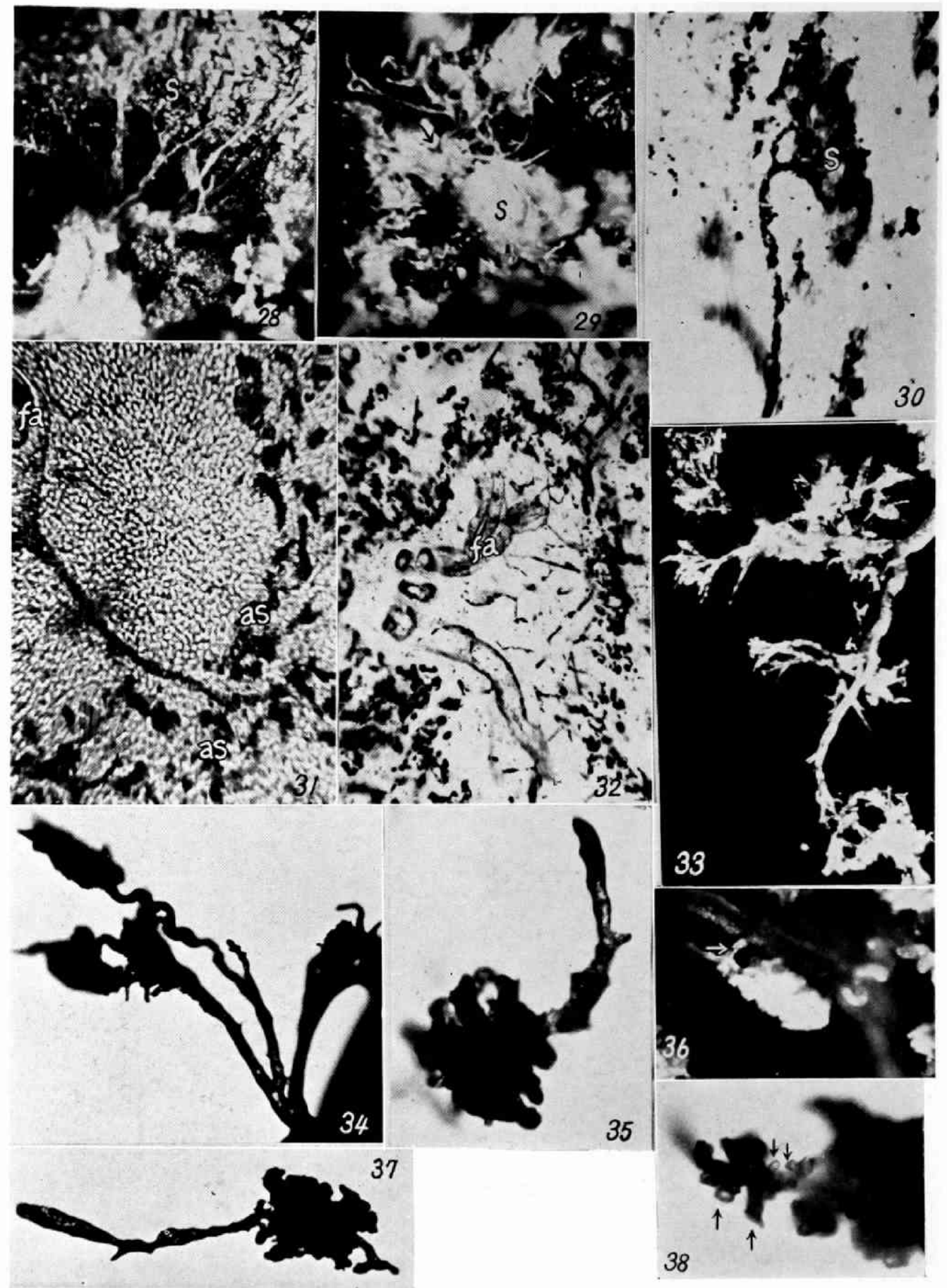




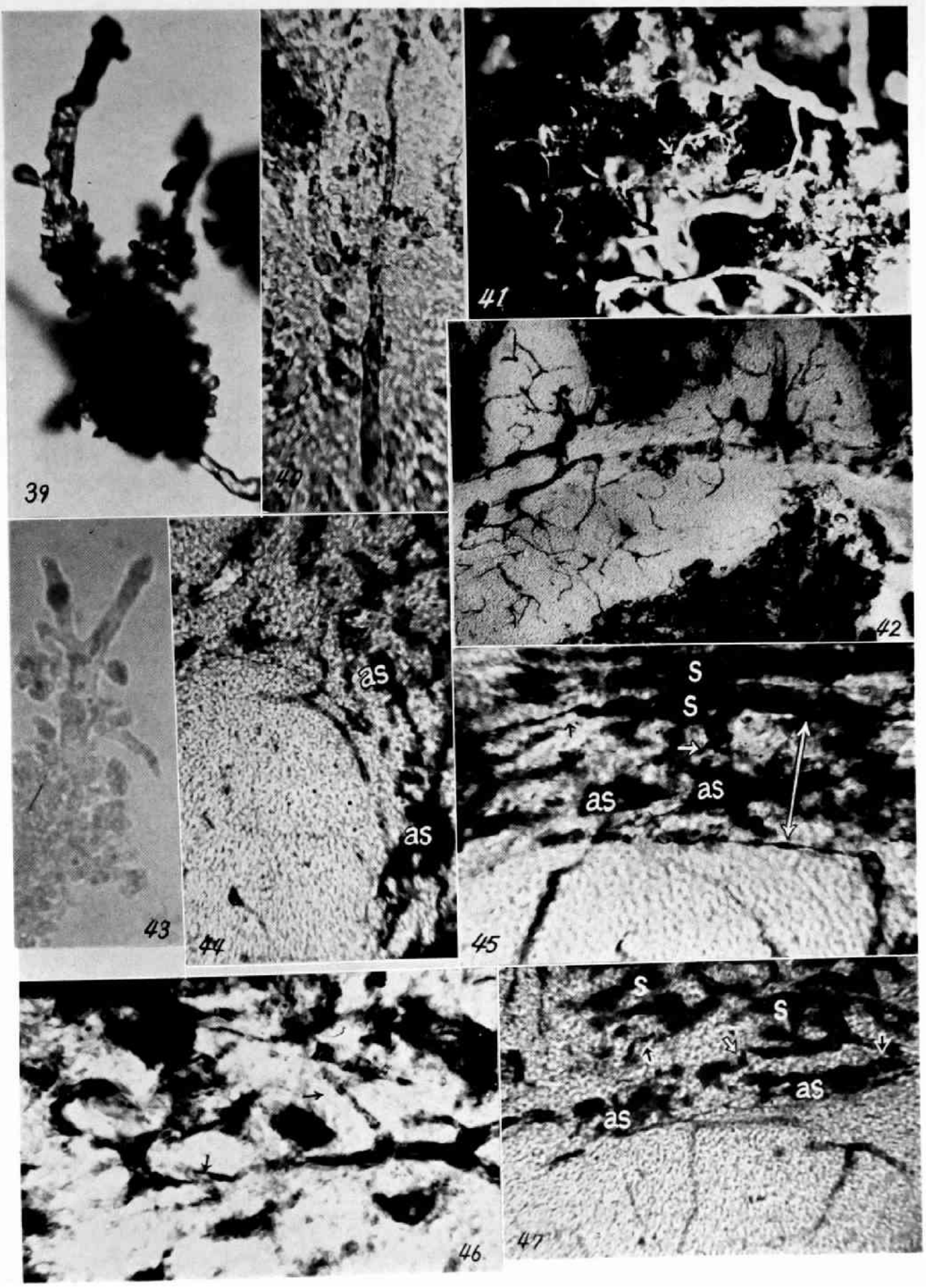


VASCULAR SYSTEM OF SPLEEN IN SOME MAMMALS

PLATE VI.

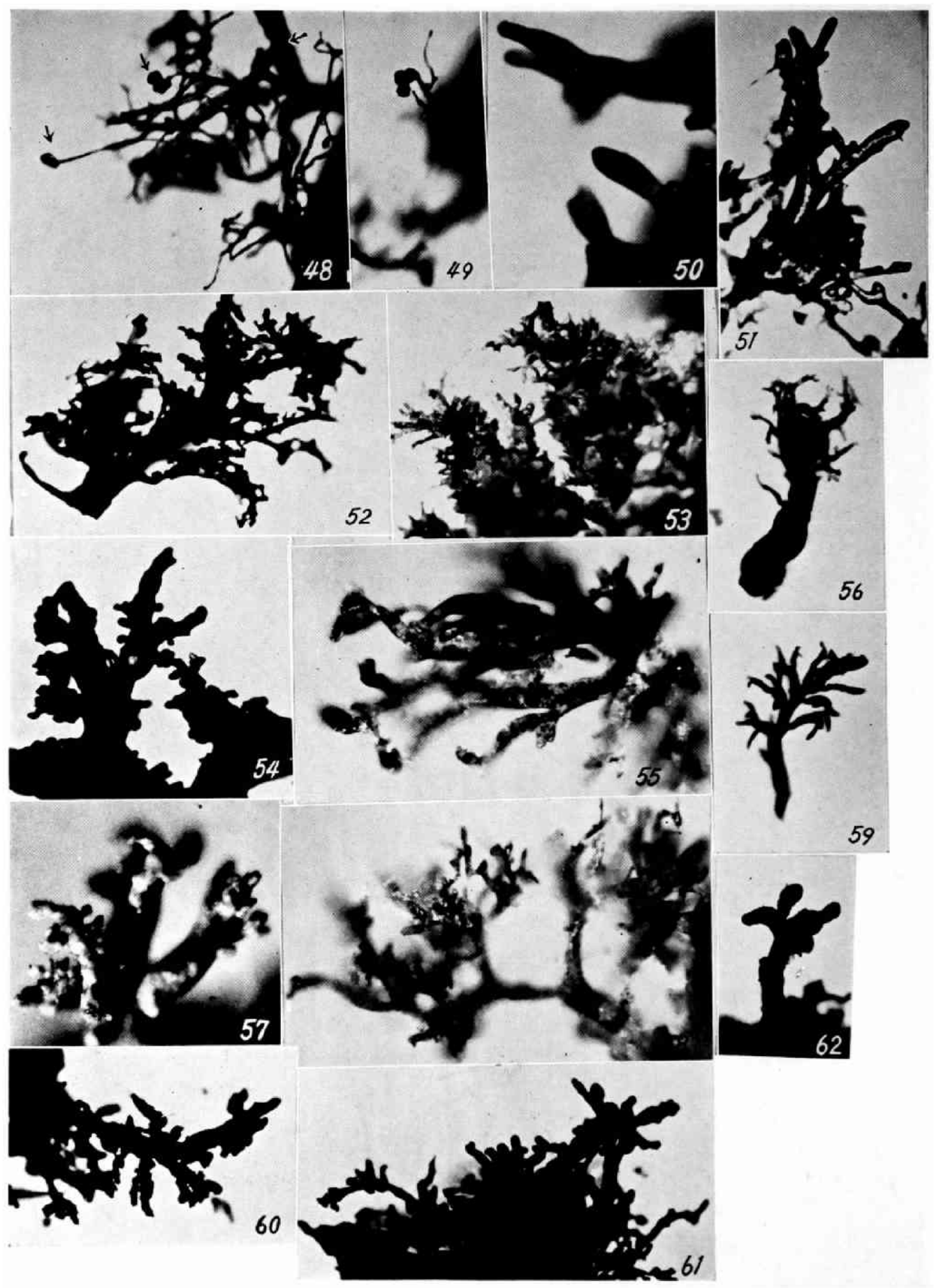

